Rodrigues, D. 2011. Cyberethics of E-Business Social Networking, In M.M. Cruz-Cunha, M.M., N. Lopes, P. Gonçalves, E. M. Miranda \& G. D. Putnik (Eds), Handbook of Research on Business Social Networking: Organizational, Managerial, and Technological Dimensions, (pp. 314-338). Hershey: IGI Global - Business Science Reference Publishers.

\title{
CYBERETHICS OF BUSINESS SOCIAL NETWORKING
}

DARIO RODRIGUES, PhD

\section{INDEX}

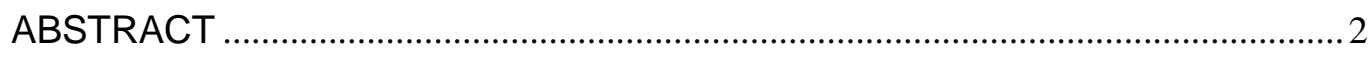

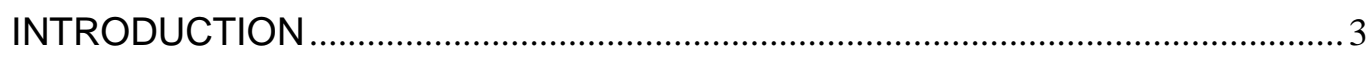

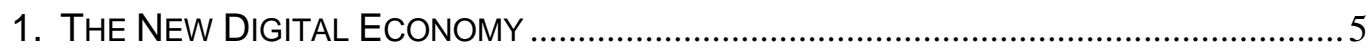

2. CYBERETHICS IMPACT OF BUSINESS SOCIAL NETWORKING................................... 9

2.1. Ethical Dilemmas Of EleCtronic MARKeting ............................................. 12

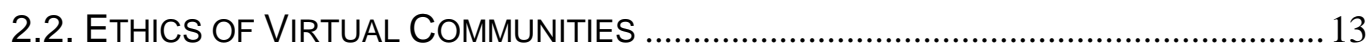

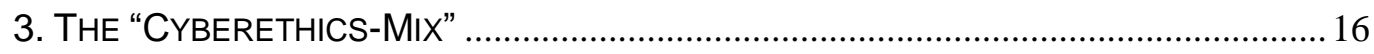

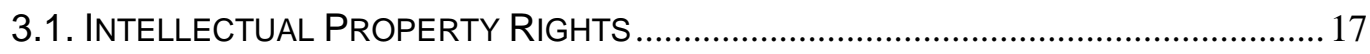

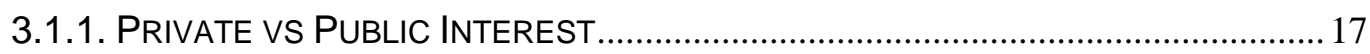

3.1.2. Opposite Strategies to Benefit From Intellectual Property........... 19

3.1.3. An Ethical ISSUe to the Civilization Progress ......................................21

3.1.4. A New Legislative Framework Seems to Be Needed ...............................23

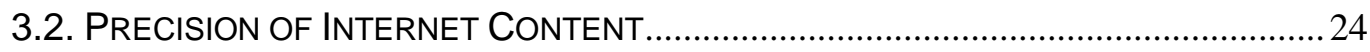


3.2.1. An EntiRely New Problem By Digital Means ….......................................2

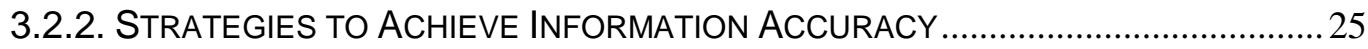

3.3. POSSIBILITY TO ACCESS THE ON-LINE INFORMATION FLOW ..............................26

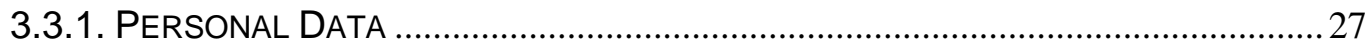

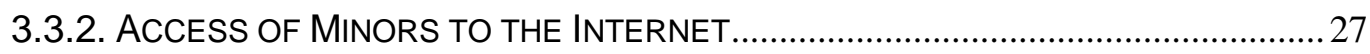

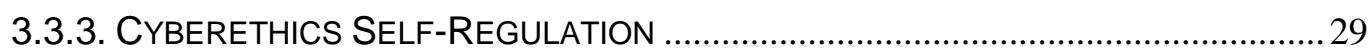

3.4. Privacy of Personal Data on INTERnet Networking ................................. 31

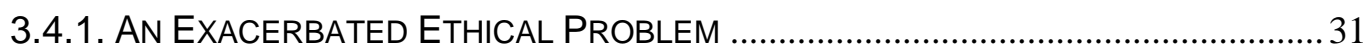

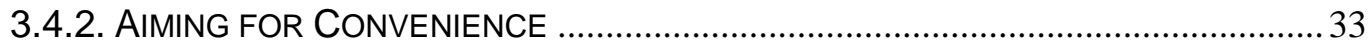

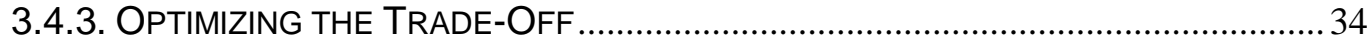

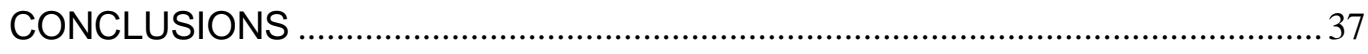

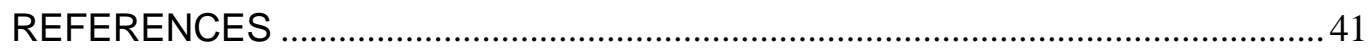

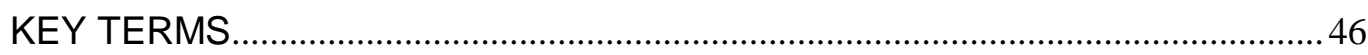

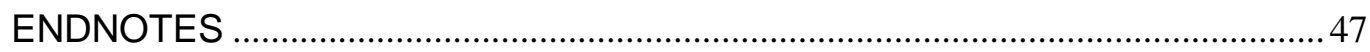




\section{CYBERETHICS OF BUSINESS SOCIAL NETWORKING}

Keywords:

"cyberethics", business networking, social networking privacy, digital paradigm, intellectual property, internet access, content accuracy, business models, low transaction costs, free, web 2.0, Metcalf Law, "digital prosthesis", electronic marketing, virtual communities, collaborative work, open code software, "digital piracy", content disclosure, misinformation, protection of minors, self-regulation, freedom of speech, trade-off. 


\begin{abstract}
The digital technologies open a virtual world where making successful business over the Internet and especially on social networks imply unusual ethical dilemmas. This chapter will seek to handle this problem, characteristic of the information age, highlighting ethical challenges surrounding the participation in a new electronic dimension which quickly became ubiquitous. In the same line of the marketing model entitled "Marketing-mix"1, a new mnemonical model is presented. This model will be designated as "Cyberethics ${ }^{2}$-mix", and is composed by four elements, all of them having the initial letter "P". These elements represent the following ethical issues that should be carefully taken into account when practicing business on the Internet:
\end{abstract}

1. Property of intellectual rights over digitized contents;

2. Precision of the content and data made available on the $w w w^{3}$;

3. Possibility to access the on-line information flow;

4. Privacy of personal data on Internet networking 


\section{INTRODUCTION}

A new digital paradigm has modified the best practices of the business world and this could be particularly true for the business practice that is made over digital social networks.

The production and distribution of bits instead of atoms allows the reduction (or even suppression) of the transaction costs that shaped the economic fabric of industrial age, making connections a lot easier, facilitating the interpersonal collaboration and a networked economy. The utility of this network seems to be proportional to the number of its users. According to Metcalf (1995), this utility increases quadratically: "For general communication networks, in which users can freely interact with each other, it has become widely accepted that Metcalfe's Law applies, and value is proportional to the square of the number of users" (Odlyzko \& Tilly, 2006, p. 1). Even rejecting this so called "Metcalfe's Law", arguing that this rule is a significant overestimate, Odlyzko \& Tilly (2006) still agree that the value of a broadcast network is proportional to the number of users. In their own words, "we propose $n \log (n)$ as an alternate rule-of-thumb valuation of a general communication network of size n. (Odlyzko \& Tilly, 2006, p. 4).

We think that the following image, proposed by Jarvis (2010), is useful for understanding the phenomenon of business webs in the information age. He sees the economic agents as being inserted "in a cloud of connections that lights up each time a new connection is created, so that the entire cloud grows more and becomes more dense, more luminous and more valuable" ${ }^{\prime 4}$ (p. 41).

We consider that such a economic environment will determine new business models. In a growing virtual world where digital networks and communities are getting bigger every day (e.g. Facebook ${ }^{5}$ ), there are several aspects that may influence the ethical direction of business practice in social networks. Wanting to contribute to clarify this subject, this chapter presents a mnemonic model entitled "Cyberethics-mix", which comprehends four ethical 
dilemmas considered important to achive best business practices on social networking in the Internet. This systematization's main purpose is to facilitate the reflection on each one of the four elements of this model, namely observing which are the ethical implications in the following aspects: Property of intellectual rights (i), Precision or accuracy of content available on the www(ii), Possibility of access to on-line information (iii), Privacy of personal data on Internet networking (iv). For example, the "Precision" element reflects a problem that is being catalyzed by the proliferation of on-line "prosumers"6, i.e. the Internet users who are responsible for the production of an increasing part of the currently available digital content.

Finally, measures are suggested to resolve or diminish some ethical problems which are being aggravated by digital means. 


\section{The New Digital Economy}

The predictions for the new information age allows us to envision an economic environment substantially different from the one that ruled the industrial age, but the points of view on the meaning of these changes are sometimes opposed.

The forecasting spectre cannot be bigger, embracing so different scenarios as the prediction of self-organized monopolies digitally induced (Murphy, 2004), or the foresight of multiple business opportunities now within reach of a large number of entrepreneurs due to the reduction of entrance barriers implied in the new digital paradigm (Anderson, 2009).

Establishing one of the most worrisome scenarios, Murphy (2004) points out that this new digital economy entails a trend of monopolistic structures spontaneous creation, likely to endanger a traditionally positive economic balance and even dramatically compromise the future performance of the economic model consecrated by the industrial age. Due to five interrelated factors, pointed by this author, the individuals eagerness and economic organizations will stop to lead the economic system to a healthy market balance, translating into a relentless self-organization of undesirable monopolistic structures.

- Economy of scale enhanced by the structure of costs: when the business costs structure has almost a complete absence of variable costs, gross margins increase exponentially with the sales volume. These generous "digital margins", translate into economies of scale much larger than those registered in traditional businesses, which could result in industrial sectors dominated by a single company;

- Pronounced learning curve in industries of technology and intensive knowledge: digital assets are easily duplicable and the marginal cost of each additional unit is very low (or 
virtually null) and for that reason the accumulation of output can be achieved more easily. However, insofar as the effect of learning and the experience curve play a significant effect in the information age, the market will tend to favour the company that accumulates output faster, making it the leader in that sector;

- "Superstar" effect, enhanced by the new information technologies: the easy duplication of digital assets, allows the consumers' brand of choice in a given sector, i.e., the brand of the company leader in that sector, to be always available for any level of demand ("shelf space" virtually infinite), hence exempting the market from making second or third choices from other companies which will then tend to disappear;

- Network effect, enhanced by the wide diffusion of the Internet: according to the so-called "Metcalf's Law" 7, the network effect makes the products or digital services more valuable as the more widespread they are. There is also the effect caused by the natural tendency for the use of standard technologies (which used in the network easily reaches a critical mass enough for self-perpetuation). Thus, once again, success creates success, consolidating the trend of affirmation of monopolistic structures;

- Costs of Research, enhanced by the volume and complexity of the information available: astounded by a multifaceted offer, consumers often opt for playing it safe, seeking refuge in known and reputable brands, benefiting the leading company and also contributing for the edification of the mentioned monopolistic structures. 
We believe that the eventual confirmation of Murphy's predictions, with such advent of monopolies in the information age, would pronounce further the ethical and regulatory problems that are presented ahead in this chapter.

But there is another direction predicted for the digital economy, implying very different conclusions from the undeniable fact that the marginal costs associated with duplication of digital assets are increasingly low.

In one of the most optimistic forecasts, Anderson (2009), admits that the cost of doing business online tends to be close to zero, arguing that the rate of online deflation is approximately $50 \%$ per year (e.g. what the submission of a video costs today to YouTube, next year will cost half). However, this author does not consider that such a scenario entails any monopolistic threat. Instead, he believes that the increasingly low costs associated with the production and distribution of bits (costs related to processing capacity, information storage and the bandwidth used to do so), enables the creation of new business models much better suited to the inexorable tendency towards "free" that characterizes the new economy. Thus, given the tremendous reduction of the marginal costs made possible by digitalization, unusual ways to negotiate successfully are emerging. For its nature, these new businesses are accessible to any entrepreneurs with the ability to think creatively about the price factor. ${ }^{8}$

Today we know that the most disruptive way to enter a market is to annihilate the economy of the existing business models. If you do not charge for a product on which the competitors depend for their profits, the world will knock on your door and then you will be able to sell something else. Just look at the free long distance calls with mobile phones [or with Skype], which destroyed the business of long distance calls from fixed lines, or think of what free [online ads] means for the newspapers. ${ }^{9}$ (Anderson, 2009, p. 57)

However, even though Anderson's point of view can fade the monopolist black shadow suggested by Murphy, it does not seem 
to be able to lessen the dilemmas and ethical challenges shimmered in the dawn of a millennium that seems to be full of new digital designs.

Knowing the important role of expectations in all business activities, it must be considered important to watch the following line of reasoning (that proved pernicious). As Keen et al. (2000) mention "online business provide enlarged operating margins that can reach up to $70-85 \%$ in purely digital business" (p. 157). Accordingly, whenever a company that operates online is able to exceed the economic break-even point, its income increases due to the high incremental margins of digital assets (associated with almost no marginal costs). The anticipation of this panorama can be so attractive to the company that leads it to make too ambitious investments in marketing and technological infrastructures to attract customers rapidly. Trying to surpass the break-even and reach such seductive margins can then become a dangerous obsession. In fact, in this endeavour, costs tend to exceed the operating results and the predicted above-average margins show themselves as being mirages. This was widely demonstrated with the stock market crash that occurred at the turn of the last century, where many start-up companies (sometimes just called dot.com) made this strategic error. According to Jarvis (2010), "In the Web 1.0 bubble, the new companies were spending too much money from the investors on marketing to pursue sudden growth, but they collapsed when the money ran out and the investors disappeared ${ }^{110}$ (p. 40).

Such a waste of financial resources, whose impact is still being felt in the economic fabric, obviously harms society and should be the cause for ethical reflection. 


\section{Cyberethics Impact of Business Social Networking}

Even long before the existence of the Internet, the impact of technology on social interactions has been the subject of prolonged investigation (Russell, 1931; Kierkegaard, 1967). For sure, the emergence and consolidation of digital social networks has increased even more the relevance of this study and intensified the need to follow through with it. For Bertrand Russell (1931), the adoption of new technologies corresponds to a change from the contemplation of nature to its manipulation. Kierkegaard (1967) goes even further, considering that the use of technology not only transforms the nature of face-to-face relationship, but also creates masks, behind which people hide from each other. According to Kierkegaard, fear is what ultimately motivates people to certain technological practices which provide people the means to escape or at least hide from those aspects of interpersonal relationships they most fear (Prosser and Ward, 2001).

In turn, the genuine interpersonal relationship, unmediated by technology, seems to be the ideal context to instil on interlocutors the maximum responsibility and respect about the content and form of what is communicated (as it is known, when relationship used to be face-to-face, many deals used to be settled eye-to-eye, "only" with a simple handshake).

It is recognized that to some extent, new forms of electronically mediated relationships forged a style of communication where the participants are mostly "read" and only a few times seen or heard. This impersonality can please some individuals, because it allows them to express their personalities without consequences, dangers and risks of a personal physical exposition (in extreme cases, it can even get them complete anonymity). As stated by Qualman (2010), "It is much easier to deal with difficult and inconvenient issues when individuals hide themselves behind instant messaging or social media comments than when they establish a face to face conversation"11 (p. 72). 
Kierkegaard (1967), Dreyfus (1999) and Szalavitz (1999), also emphasize the fact that the new communication technologies may serve to hide or maintain certain anonymous aspects of the being (which would also strengthen the ethical imperative in the virtual world...). However, we think that this dissimulation effect should be considered only collateral, and should not obfuscate the emphasis that must be given to other type of consequences, which impact on Business Social Networking is considered much more relevant, involving the creation and emancipation of virtual communities who seem full of life. None the less, from an ethical point of view, it is deemed pertinent to observe the thought of the referred authors, because the intrinsic intangibility of the virtual world (with, undoubtedly, a lower personal commitment or even the anonymity of those who participate in it) may encourage a lack of seriousness and dilute the sense of responsibility and authenticity indispensable for the construction of a healthy and transparent social-economic fabric.

On the other hand, observing the current speed of technological progress, the evolution of electronic interfaces will be accelerated almost for sure (e.g. voice interface and 3D holographic imaging), resulting in a greater realism of the electronically mediated relationship. It is even possible to think that such relations can reach the level of personal commitment achieved in the physical interpersonal relationship. However, one may think that the increasing sophistication in terms of "avatars"12 can strengthen the intangibility of the interlocutors and complicate the whole situation (as predicted by Kierkegaard and corroborated by his followers).

That said, we consider that the biggest purpose inherent to the development of information and communication technologies will not be to hide certain aspects that individuals would wish to conceal, but to increase the level of the overall performance achieved in their relationships.

Digital social networks, such as the Internet itself, can function as instruments or "digital prosthesis" capable of making individuals more productive. As stated by Natali Del Conte ${ }^{13}$, quoted in 
Qualman (2010), "I truly believe that, ultimately, Facebook and other similar platforms will be not so much a destination but rather a tool that we can use wherever we are and that will connect us to other portions of the $\mathrm{Web}^{114}$ (p. 239).

We fully agree with this analysis, and believe that the real driving force of any technological innovation is the economic convenience, and not an obscure psychological determinism based on the "fear of humanization". We consider that the lack of trust, installed in the social fabric when using new technologies, arises from the still rudimentary level of relationships experienced in the virtual world, where interactivity has not yet reached the realism achieved in "face-to-face" relationships. This advises to perform an ethical reflection and adopting measures that allow the reduction of the uncertainty and insecurity for the users (e.g. in the processing of online transactions) and strengthening the confidence in business practices on social networksg.

We think that there are three ways that can help to solve the lack of confidence problem:

(i) Educating users about subjects related to privacy, content accuracy and online safety;

(ii) Producing a legislative framework that protects the business partners (e.g. in terms of intellectual property);

(iii) Developing technological systems designed to protect users and their possibility of access to Internet content (e.g. data encryption, digital signatures, filters, etc.).

In point 3 of this chapter, we observe these and others solutions. 


\subsection{Ethical Dilemmas Of Electronic Marketing}

The use of electronic marketing instruments raises a whole new series of ethical problems.

It is common knowledge that e-mail is the most used instrument of electronic marketing. Obviously, its conspicuity is related to a large extent with the low cost involved.

We believe that there are two distinct ways of looking at the use of e-mail marketing: the first, recommendable from an ethical point of view, corresponds to its use only and exclusively when actual and potential customers show their agreement or expressly request it. This manifestation of willingness on the part of the customers, can be expressed directly through website registration and e-mail requesting (e.g. in the form of newsletters). Another possibility is the obligation to accept e-mails as a counterpart for certain services or offers (e.g. a free subscription to an e-mail account). This way of looking at the use of e-mails as a marketing tool, can be criticized from an ethical point of view whenever is done without the knowledge of their recipients This is what happens when systematic sending of unsolicited e-mails occurs. Many of these e-mails annoy its recipients, being this practice (denominated as spamming), usually motivated by the minimal cost involved in obtaining new email addresses and by the low marginal cost of each additional contact.

Another ethical problem that may be raised by electronic marketing relates to the use of the so-called cookies ${ }^{15}$.

These electronic marketing instruments can be installed surreptitiously and the data they collect (e.g. identities and purchasing habits) may be sold without the consent of users.

We really believe that beyond certain measures of positive ethical impact (e.g. digital signatures, certifications and online seals, etc.), the main source of solutions to promote electronic marketing 
ethical regulation will be the market itself.

The Internet is promoting (and being promoted by) the conversation between humans and we are witnessing a global word-of-mouth. Therefore, information about any kind of online traders dishonesty, is rapidly spread around the world, and is thought that the approach many-to-many ${ }^{16}$ is very effective from the point of view of ethical commitment. With the resulting growth of the blogosphere ${ }^{17}$ and the social media ecosystem, with the formation of increasingly bigger virtual communities, this transparency and ethical commitment tends to increase, with obvious impact on the business world. Probably having this in mind, Bonson, E., \& Flores, F. (2010) stated that "Social media encourages corporate transparency" (p. 23), and Jarvis (2010) stresses that there is an inverse relationship between control and confidence, referring that the more information the company controls less people trust it. For this author, "Transparency will build a trusting relationship with customers and open new opportunities. [The ethics of transparency implies] the need to involve customers and transfer control through opening and information disclosure, the participation in open-source networks, the adherence to an economy of supply and the ability to listen."18 (Jarvis, 2010, p. 118).

Hence, it is deemed appropriate to address the ethical dimension that should nurture the growing number of virtual communities in the Internet.

\subsection{EThics OF ViRTUAL Communities}

The success of a whole new generation of companies and respective platforms on the Internet, illustrates well the importance that users attribute to the use of digital tools that can help them to organize themselves into virtual communities that facilitate the pursuit of their specific purposes. 
Such successful companies help their clients to organize themselves around what they want to do or achieve, trying to anticipate their needs instead of trying to control them. In the same way, these new companies do not create communities but facilitate the respective mission. As stated by Jarvis (2010), quoting Mark Zuckerberg ${ }^{19}$, "Communities are not created [...] communities already exist. They are already doing what they want to do. The question that [the founders of a community] must be made is how they can help them do it better"20 (p. 60).

The Linkedln community ${ }^{21}$ organizes its members around professional goals; Facebook ${ }^{22}$ organizes its members around personal goals; Flickr ${ }^{23}$ facilitates the organization of photographs of their users; Skype ${ }^{24}$ provides the tools for its clients to organize themselves together through telephone and videophone; Twitter ${ }^{25}$ organizes the way for its users to express their status in 140 characters, etc. It is thought that what these companies have in common is the fact that they act according to the specific purposes of their customers. However, although there are huge communities that gather around them, the owners of these communities did not create nor dominate the gregarious spirit and initiative of its members. In this regard, it is considered worthwhile to continue to observe the words of Mark Zuckenberg as quoted by Jarvis (2010):

When a community gathers around you, be aware that you are not its owner, the community owns itself. [...] communities are already doing what they want to do. If you're lucky, they will let you help them. [...] The new generation of organizational companies Facebooks, Flickrs and Wikipedias - do not organize us. They are platforms that help us organize ourselves." ${ }^{26}$ (Jarvis, 2010, pp. 6265)

Traditionally, the predominance of secret or closed programming standards made impossible for third parties to program interfaces between programs and applications created by different organizations. These entities and respective applications remained stagnant because secrecy was considered to be "the heart and 
soul" of any business. Apparently, this is no longer true with the generalization of open code software and opened API (Application Programming Interfaces) that clearly specify the details of the interaction between independent programs belonging to independent companies or programmers.

Currently, many of these $A P I$ are immediately unmasked by the companies or individuals that created these programs and applications. Here too, the company Google has revealed a pioneering vision, by unveiling many program codes and by making these programs available for integration into multiple applications.

It should be noted how this new reality allows programmers to get more recipients for their applications and enables users to obtain more applications for their purposes. This is the case when considering the number of new applications that daily appear on the Facebook social network or on iTunes platform (and immediately after in iPods and iPhones).

It is believed that it is very important to understand this inexorable tendency of openness and participation, because in competitiveness path in the current business environment, companies are increasingly dependent on foreign intelligence, being natural that their degree of "porosity" in relation to this precious intelligence will increasingly become an important condition for success. In this line of reasoning, Tapscott, D. (2007) considers that "the winning companies will be those that are able to encourage and guide symbiotic relationships with the emerging structures originated from the market, either facilitating the creation of relevant applications or facilitating its eventual articulation from the point of view of their users." 27 (pp. 54-55)

Probably the most popular on-line applications will be those that maximize the virtual community population coverage due to its intrinsic utility, accessibility and ergonomics. Such a high level of participation increases even more the responsibility of ethics in these new applications, guiding them with rules and principles capable of protecting various aspects related to equity among its 
users concerning the possibility to information access, the range of actions that can be performed on-line at each level of privilege to ensure the privacy desired by each user, and to guarantee the capacity of every member to be aware of information precision provided in the community, creating instruments to facilitate the scrutiny of its accuracy (e.g. as being done at Wikipedia ${ }^{28}$ ), and, finally, to prevent the misappropriation of intellectual property within community boundaries.

We argue that probably these are the major ethical challenges arising from the business use of social digital networks. Therefore, the following pages look into these ethical dilemmas, using the mnemonical nomenclature ${ }^{29}$ of four "P" entitled "Cyberethics-Mix".

\section{ThE "CYBerethics-MiX”}

As mentioned earlier in this chapter, the following group of ethical dilemmas will be named "Cyberethics-Mix", a mnemonical model which comprises four elements, all of them having the initial letter "P":

1. Property of intellectual rights over digitized contents;

2. Precision of the content and data made available on the www;

3. Possibility to access the on-line information flow;

4. Privacy of personal data on Internet networking.

These "cyberethical" problems will be now examined. 


\subsection{Intellectual Property Rights}

\subsubsection{Private vs Public InTerest}

The contemporary discussion about intellectual property revolves around the dichotomy between the protection of ownership rights and the public interest.

The creation of a particular work often requires the use of time and money, therefore the desire to ensure some return for that investment may be of an unquestionable legitimacy and appear ethically unpolluted.

On the other hand, it also seems easy to justify the social role played by free and rapid dissemination of public information (e.g. the discovery of a new medicine). The apologists of this theory maintain it by arguing that the ideas belong to all mankind and that only the expression of these ideas can be considered as belonging to a particular individual. Being so, that individual would not make more than to use and give expression to the accumulated knowledge of society, often relying himself directly on the work that others did before him.

Anyway, regardless of ethical arguments or value judgments, there is a pragmatic reasoning that should not be ignored: any information coded in binary language can be easily duplicated. In fact, it is virtually impossible to prevent someone from making digital copies. Additionally, the Internet is for sure the best platform to ensure their ubiquity.

To the contrary of what happens with physical and tangible assets, such as a house or a car, the transmission or cession of digitized assets does not imply the inexorable loss of the possibility to use them (differently from what could happen in the case of physical assets, like the music in the old vinyl discs; unlike older people, youngsters don't need to wait around for the return of his favourite 
music when it was sent by e-mail or shared on a social network on the Internet).

Similarly, to pass knowledge never meant to lose it. However, nowadays, by means of digital duplication, the conspicuity of this knowledge keeps increasing, and the respective exclusivity and market value can decrease irreversibly in the perspective of its original owner.

This facility of reproduction, inherent to the fact that marginal costs of digital duplication are nearly zero, might seem favourable to consumers and to society in general. However, for some, such a scenario brings the discouragement of the producers of any assets that can be digitized, probably increasing their reluctance in assuming a scale of production and distribution costs that is well above the marginal costs of digital reproduction of the same goods. Still following this perspective, this is especially true when such reproduction can be made with impunity by third parties.

However, one can argue that the so called "digital piracy" also increases innovation. For instance, as showed by the recent development of 3 Dimensions (3D) video technology, we can think that without "digital piracy" the film lovers have not had 3D TVs... given that these devices emerged in response to needs felt by the film industry in presence of massive films piracy. With 3D films, came the 3D TV, as simple as that!

One can think that the disenchantment felt by the creators and owners of the intellectual property is perfectly understandable, because can be considered unethical to "harvest the fruits" in detriment of who began the "sowing". But what will happen if the following "harvests" can be made by everybody without losing the next "seeds" or even increasing their potential... what should we think about it then? We really consider that this issue deserves further investigation and also more political opinions. 


\subsubsection{Opposite Strategies to Benefit From Intellectual Property}

One of the ways often used by the producers of goods that can be digitized to circumvent this problem, has involved an attempt to artificially increase the marginal costs of digital reproduction of goods produced and distributed by them, namely by moving legal actions against those who promote such reproductions. The case of the website napster.com ${ }^{30}$ was just the first, having appeared other cases (as the recent sonant process filed against the Norwegian website called piratebay.org).

Meanwhile, other producers chose to give another kind of answer to face this threat to their intellectual property rights, being this a solution particularly interesting in terms of electronic business (ebusiness) and social networking. For example, the Massachusetts Institute of Technology - MIT, given the intellectual property vulnerability of educational institutions, instead of focusing on ways to accuse any "wrong-doers", it decided to dispose freely on the Internet the contents of almost all courses in the institution (including manuals, notes from the teachers, exercises, exams and even videoconferences). This project, entitled "OpenCourseWare", can be found on http://web.mit.edu/ocw/ ${ }^{31}$.

The doubt about the viability of this type of solution comes naturally. After all, how can one profit from offering a university level free education? For Jarvis (2010) the answer to this question involves several findings:

- A college education is much more than attending lectures online and carry out readings... In fact, in addition to the academic titles (which cannot be obtained through a YouTube channel...), physical interaction with teachers and classmates is still truly irreplaceable for sharing and exchanging ideas, seeking feedback, answering questions, etc.

- The contents disclosure can serve as an excellent marketing 
instrument (especially in the digital world) regarding the mission and even in the business perspective of university institutions;

- The offering of contents endows teachers with an exposure almost impossible to obtain in the physical world, which can bring them an added notoriety and enhance their reputation, opening the way for lectures, books, blogs, etc.

We agree with the position expressed by a growing number of authors (Tapscott, 2007; Qualman, 2010; Anderson, 2009; Jarvis, 2010), who antecipate the occurrence of business models that will be substantially different from those that have prevailed in the industrial age. As stated by Jarvis (2010), "The world is upside down, inside out, is counter-intuitive and confused. [...] We have moved from an economy based on scarcity to an economy based on abundance. The control of products or distribution is no longer a guarantee of bonuses and profits" (pp. 9-10). Anderson (2009), goes even further, pointing that "the only thing that sustains the price [against the "gravity force" of the new digital economy] is intellectual property law"(p. 270). To him, the enormous ease with any person can copy certain goods, whose intellectual property was traditionally protected, will inexorably bring down the prices of those goods to zero (Anderson, 2009). Agreeing with this prediction, we believe that the most successful economic models in the information age will be those that work in accordance with this premise somewhat counter-intuitive:

The schemes for intellectual rights protection encoded either in the law or in the software are simply holding back the price against the force of gravity. Sooner or later, [that price] will go down because the owner allows [as in MIT case] or because the pirates lay it to the ground [as in the PIRATEBAY.ORG case] (Anderson, 2009, pp. 271272) 


\subsubsection{An Ethical Issue to the Civilization Progress}

In order to better observe the civilizational scope of the contemporary problematic of intellectual property, we think that can be useful draw a parallelism between the business world and the biological world. As mutations permit a rate of inter-individual variability that is crucial for the successful evolution of species, it could be thought that creative entrepreneurship, based on innovation and not on faithful reproduction, is the only guarantee of company adaptability to markets in constant change ${ }^{32}$. In this view, innovation is for companies what mutations are for life. One can think that if the first "Ford T" car model had been "cloned" throughout the years without significant costs, perhaps it could still be sold, being today cheap and abundant. However, probably the cars today would no longer be a universal transport, because if the marginal cost of "cloning" each car was virtually nil, one can speculate that many models of car would not have been produced from scratch and cars no longer could present its great diversity.

On the ethical and economic points of views, one can think that this probability of stagnation is a major risk arising from the extreme ease that digital goods are reproduced, and that this may even undermine the traditional and healthy industrious nature of free societies.

However, as we know, bits are different from atoms and digital information is much more open to creative combinations than physical items and perhaps this new plasticity should not be impaired by legal restrictions still adapted to the industrial age.

It seems clear that it is urgent to reflect and review a system that seems not to be properly designed to address the problems posed by the easy reproduction of digital content and by the daily sharing of information. Furthermore, these aspects have become fundamental requirements of competitiveness, seeming no longer to assume the gravity or even deserve the traditional censure. In the words of Jarvis (2010), "The public nature is also becoming a key attribute of successful businesses. Today, we live and do business 
in homes (and offices) with glass walls, and this is not necessarily bad. [...] the public nature is also an ethics" (pp. 56-57).

It has been mentioned earlier the current dependency of companies relatively to the existing intelligence on their outside, as well as the need for these companies in promote their "porosity", openness and participation capacity. Only this way they can become able to benefit from the potential for innovation that results from digital collaborative work, increasing this way its own competitiveness.

In the new digital paradigm, many services are emerging in the Web $2.0^{33}$ thanks to the creative combination of programs that are equivalent to construction blocks. These programs are now becoming functionally articulated in new applications which are meant to be more competitive. As an example, we can look at the combination of the applications available in GoogleMaps.com and in CraigList.com, which are the foundation for the successful service offered on the website that can be found at housingmaps.com.

As it is known, the register of intellectual property rights and the protection of patents have been the traditional ways to ensure the profitability of many businesses. However, is also true that issues related to the business models hardly follow the same rhythm of the technological innovation current speed. It is believed that due to the referred requirements of business competitiveness in the information age, the risk of transgressing certain intellectual property rights can be an inhibiting factor to business success, namely by preventing the combination and creative mixture of components based on intellectual property of others and impeding the creation of more valuable products and services. As mentioned before, we think that in order to achieve business success in today's competitive environment, it is necessary to let companies benefit from the intelligence that exists outside them (obviously always more important than the one that lies on the inside). Being so, the decisions about what should be kept inside and what should stay outside the company's frontiers, are becoming essential for articulate resources and to obtain synergies that could be translated into truly competitive solutions. In a market increasingly open and 
collaborative, we think that those solutions tend to result from partnerships and business networks of increasing fluidity.

\subsubsection{A New Legislative Framework Seems to Be Needed}

In a world where transaction costs are being reduced and the collaborative work becomes more and more indispensable, as it can be verified by the increase in the average number of authors per scientific document (Newman, 2000), it would therefore be expectable that the legislation related to intellectual property rights would evolve in conformity with the new requirements of competitiveness. This development is already in progress with the licensing Creative Commons, created in 2001:

"[The Creative Commons Licenses] allows the expansion of the number of works available for free and stimulate the creation of new works based on the originals, in an effective and very flexible way, by resorting to a series of standard licences that ensure the protection and freedom - with some rights reserved. The Creative Commons Licenses are between the ownership rights (all rights reserved) and the public domain (no rights reserved). They have a worldwide scope, are perpetual and free. Through Creative Commons Licenses, the author of a work defines the conditions under which the work is shared, in a proactive and constructive way, with third parties, and all licences require that credit is given to the author's work in the way he specified."

(“CreativeCommons", 2010, para 2 \& 3)

Contrary to the previous legal framing, we consider that this type of non restrictive approach to intellectual property rights is in line with digital business requisites and it is much more favourable to business practicing in the information age. 


\subsection{Precision of InTERnet Content}

\subsubsection{An Entirely New Problem By Digital Means}

Willingly or unwillingly, it has never been so easy to induce or be induced in error as in the information age, because it has never been so easy to access or distribute information.

The transmission of data on the Internet can serve to obtain and divulge false or incorrect information and also for manipulate or to be manipulated, even by true information. The consequences of these types of misinformation can reach dramatic proportions, since the information conveyed in these networks serves as input for decision-making processes of high involvement (e.g. health related decisions).

Moreover, the misinformation on the Internet is different from what occurs in traditional media such as television, newspapers or radio. One of the biggest differences is related to the level of misinformation. It's easy to understand that the impact of misinformation is correlated with the number of issuing sources. On the Internet, where there are lots of content providers, especially with web 2.0, even a reckless child can diffuse information in a good looking website... Obviously, this decreases the reliability of the information released on the Internet. Another difference from traditional media, is the reliability and credibility of the emitting source; unlike the traditional news media, which are "bricks and mortar", the content providers on the Internet can be anonymous or only have a virtual identity. Additionally, we think that in the near future, with the so called "semantic web", the virtual world will be characterized by a minimum of human intervention in the transmission of information, which probably will be carried out by using digital agents based on systems of artificial intelligence.

Finally, on the Internet there are no intermediaries or gatekeepers such as publishers, libraries, known speakers, etc. This lack of 
indicators hampers the assessment and certainly contributes to the so-called misinformation. Moreover, the increasing availability of information on the Internet may result in the blurring of the distinction between the important and the trivial (just observe the need to "separate the wheat from the chaff" in so many e-mail boxes). Considering the growing inability to discern the accuracy of information disseminated on the Internet, it should be emphasized the importance of knowing how to distinguish what it is or it is not important and true.

\subsubsection{Strategies to ACHIEVe Information AccuRACy}

Pursuing to solve the plague of misinformation on the Internet, we think that two independent strategies can be distinguished:

- Prophylactically develop the critical sense of "Internauts". We believe people can be taught not to trust everything they see on the Internet and to maintain a certain intellectual distance concerning web contents.

- Create reliable indicators about the authority, fiability and credibility of content providers, either by obliging them to meet certain transparency requirements (e.g.: inclusion on the website of a web page solely dedicated to the detailed presentation of it), or by using third party certifications. These "trusted third parties" (e.g. Verisign, findable at www.verisign.com) are equivalent to the notaries of the physical world.

We think that social networks as well as many Web 2.0 applications (e.g. google.com, digg.com ${ }^{34}$, delicious.com ${ }^{35}$, etc.), are, fortunately, that kind of digital instruments that can rapidly show the popularity and the acceptance level of the available content, allowing each user to have access to what have been called "the wisdom of the crowds" (Surowieki, 2004). This democratic criterion of popular 
validation can be very useful and we agree with Surowiecki (2004) when he states that the public in general - users, clients, readers, students, audience, neighbours - is wise. This belief can be underlined by alluding to Google's search engine which uses an extremely successful algorithm, called PageRank ${ }^{36}$, that uses the popularity of content to calculate and determine its relevance; after all as Jarvis puts it, "Google has faith in the data because it has faith in us"37 (Jarvis, 2010, p. 108).

\subsection{POSSIBILITY TO ACCESS THE ON-LINE INFORMATION FLOW}

Another element of the "Cyberethics-mix" is the possibility of access to information diffused on-line, namely over the Internet. This issue relates to the question of knowing which limits and rules that should govern the users access to the Internet.

We hope that the legislator who intends to regulate the access to the Internet, does so keeping in mind the fact that the ubiquity of information technology can and should make the world more human.

Nobody should doubt that computers are powerful instruments and precious resources in the pursuit of individual and organizational goals. The problem is to determinate whom should have access to this resource and in what circumstances it should be distributed in society.

To answer this question properly, we considered important to start from the presumption that individuals with access to an instrument as powerful as the Internet, will always be in a better position to achieve their objectives. Indeed, one concern regarding the social effects of computers is the fact that they could increase the cleavage between the more and the less favoured individuals, and the gap between "have" and "not to have" may become the abyss between the "knowing" and "not knowing". 


\subsubsection{Personal Data}

Still related with the possibility of access to information stored in various databases and divulged on the Internet, is the problem of knowing if any individual is entitled, or not, to access, read and modify personal data concerning its own person. Once again this is a controversial issue. If it is true that the possibility of, for example, update or correct an error detected in the data itself looks unpolluted, it is also reasonable to invoke the need to ensure the integrity of the information and to prevent, for example, the possibility of an individual to falsify his own identity records.

A possible solution for this problem is the commitment to a "code of ethics" ruled by high standards (at national and international level), that reassures data protection. There are already several examples of legislation aiming to regulate the procedures for gathering and storing data.

\subsubsection{ACCESS OF MINORS TO THE INTERNET}

Perhaps the most delicate subject under the ethical point of view regarding the possibility of access to the information is related to the access of minors to the Internet. As we know, an irresponsible access can affect the emotional and cognitive development of children and adolescents, leaving more or less severe squeals.

Observing this problem from a consumer point of view, especially when business on digital social networks involves (direct or indirectly), his household or family, we should note that there are some methods to protect minors from accessing certain websites, for example, those with content exclusively for adults (e.g.: businesses involving pornographic websites). Unfortunately, it is known that it only takes to press a few buttons to activate and deactivate most of the available filters, and there is the risk that this task may become more trivial for children than for adults... Anyway, it should be pointed the good examples of programs like Net Nanny, 
CyberPatrol, Cybersitter and SurfWatch, to filter out inappropriate material. Obviously, any kind of software with regulatory impact does not obviate the need for parental supervision in the virtual world (just like happens in the physical world, here parents who esteem themselves do not take their children to establishments prohibited to minors). Although it should be determined mainly by common sense, this supervision can become more effective when some standards are observed. Begg et. al, (2001) advocate the following rules of conduct for a successful parental supervision:

(i) Opt for the acquisition of an affordable universally accepted hardware/software. Although the argument that this attitude favours the monopoly of certain companies can be used, this is, in the perspective of the families, the most appropriate behaviour;

(ii) Create an appropriated physical area of work/leisure for the computer's location. This should never be in the children's room. It is convenient that the monitor is always visible to the "casual" look of the adults;

(iii) Establish time boundaries for the different activities carried out in the computer (work, participation in social networks, etc.). Adults should also adopt this kind of self-discipline;

(iv) Not allow the frequency of groups in social networks without proper parental supervision (such as in the physical world, no more no less). Do not forget that some paedophiles, for example, use these and other groups to make offers and give presents or incentives to children in order to allure them to join activities that may seem perfectly innocent;

(v) Supervise the adhesion of children to applications that require the filling of online forms with personal data;

(vi) Do not allow children to visualize posts on blogs, open files attached to e-mails or make downloads of something when its origin is not perfectly clear.

(adapted from Begg, et. al., 2001) 
Complementing these and other individual efforts, several kinds of software with regulatory impact may, once again, play a predominant role in a decentralized ethics self-regulation of the virtual world.

\subsubsection{Cyberethics Self-Regulation}

An approach based on cyberethics self-regulation, enables professionals and Internet users to contour aspects that escape "the invisible hand" of the market ${ }^{38}$, and to spare the high transaction $\operatorname{costs}^{39}$ associated with the centralized kind of regulation (e.g. measures of governmental coercion).

The ethics self-regulation of the virtual world, based on the prudent use of a proper software programming, seems to have the advantage of preserving individual choices and suppress undesirable effects without incurring in high transaction costs. In fact, the most powerful regulatory force in the virtual world is not the market nor the law, but the software code. It seems reasonable that this code, while key-factor to the prevention and resolution of problems through ethics self-regulation in the virtual world, must meet certain requirements to ensure its moral competence, especially because a "force of law" is delegated in it (Lessig, 1999). Indeed, it is the programming code of a computer program that determines the users freedom.

In order to ensure, in a responsible manner, the development and installation of a software programming code which is desired unpolluted $^{40}$, Spinello (2001) suggests that the software programming code should be as open and transparent as possible, so as to respect the autonomy of the users, allowing them to make conscious choices and to express an informed consent. This author alerts for the fact that, contrary to the law, whose publication is mandatory (it can be imagined what it would be if the laws or the legislative process itself lacked transparency), the software is often 
camouflaged by obscure lines of confidential code. Obviously, this can result in a subtle manipulation of the users (the rough manipulation, easier to detect, is not as disturbing). For example, when parents buy a specific type of filter to protect their children from pornography, they may never know that the software also blocks access to websites dedicated to sexual education or family planning (Spinello, 2001).

This author underlines that the software programming conceived to condition the access to the information divulged on the Internet, should be made in a way that can preserve the traditional moral and social values such as freedom of speech and personal privacy.

We think that social order on the Internet should not be achieved at the expense of ethical values, and there should be a reasonable proportionality between the size of the problem to be corrected and the solution found to solve it. For example, developers should avoid disproportionate answers that undermine values such as the already mentioned freedom of speech. Thus, individuals and organizations that use these programming codes must do so always in the least restrictive way possible. For example, the task of preventing the access of minors to certain contents does not justify restricting the adults from accessing it. On the other hand, ethical regulations based on software programming code must be made available downstream and not imposed upstream, i.e. they should be established preferably at the individual or organizational level, and not at the level of each Internet access provider or country legislation (just consider the known limitations in China concerning full Internet access), because such a use of this powerful regulator instrument upstream could seriously restrict the inviolable ethical principle of free will (Spinello, 2001). In February, 2011, during revolutionary events in Egypt, Google and Twitter reached an agreement that enabled the "tweeting" practice in off-line mode, and those who were being info-excluded due to the national security state in Egypt, immediately started to have full access to Twitter on the Internet with a help of a simple phone line connection. 


\subsection{Privacy of Personal Data on Internet Networking}

Last but not least, let's consider the final letter "P" of the "Cyberethics-Mix", which stands for the element "Privacy".

This is perhaps one of the most flagrant challenges of ethics in the information age, because one of the major concerns of Internet users is the eventual attack on their privacy.

The concept of Privacy can be connoted with a right that Samuel Warren and Louis Brandeis (1980) called the "right of the individual to be let alone" (p. 2). These authors think that someone's privacy depends on whether the capacity of others to influence or provoke an impact on his life, or the capacity of others to know things about his life (Warren \& Brandeis, 1980). In other words, as less is the influence or impact of others on the life of an individual and few are known about him, the more privacy he will have.

The right to personal and family privacy has been considered one of the most basic rights of individuals. Thus, given the development of technologies for processing and transmitting data, it is understandable why the violation of privacy has become one of the most preoccupying aspects in our society. In this sense, Bertrand Russell (1931) already considered that technology consists of a change from the contemplation of nature to its manipulation, and that such a change carries risks (Marturano, 2002).

\subsubsection{An Exacerbated Ethical Problem}

It seems obvious that the advent of the Internet opened new routes of access and disclosure of intimate and private spaces. Therefore, there is the risk that the lives and societies become transparent and that people will start to live into "glass houses".

In the industrial age, the traditional limits of surveillance were 
guaranteed, to some extent, by the fact that everything had to be processed by humans. For this reason, many people have been necessary just for look at the surveillance cameras or listen to the phone calls.

Thus, the surveillance that could be made on a given population was largely determined by the proportion of the population employed to carry out that vigilance.

On the contrary, in the $21^{\text {st }}$ century, almost all the data that is relevant to the privacy of individuals are gathered and digitized, either to save time and money either to generate profits. In fact, the new information and communication technologies provide easy ways to record and inspect these same data for many years. Additionally, certain events (like the dramatic incidents in New York on September 11, 2001), can catapult this effort of surveillance and pose even greater ethical dilemmas. As a result, it seems that the complexity of the problematic related with the privacy of Internet users is dramatically increasing and several ethical issues are rising in this dawn of the third millennium.

Nowadays, personal data is being provided to the most varied entities for the most various reasons. As we know, nobody can guarantee that the route of these data always corresponds to the path and destiny announced by those who collect them, and some individuals and organizations can cede to opportunistic impulses and try to achieve their interests at the expense of others privacy. And it is not just the misuse of data that is worrying, because the personal data voluntarily disclosed to different institutions, once combined, can give a so complete image of the citizen that perhaps he would prefer that it wasn't public. For example, a person can look favourably to the guarantee that the information revealed to his doctor or to his bank manager do not entering into the public domain, however that person would still be concerned with the impact on his privacy if his doctor could access his bank records, or if his insurance company could know his medical records, even though knowing these two entities will not disclose such information to anyone else. 


\subsubsection{Aiming fOR CONVENIENCE}

Especially in this Business Social Networking context, we think that it is important to mention the loss of some privacy as a tolerable downside of getting and securing a greater convenience. As we know, particularly in marketing terms, our needs can only be fully satisfied after being well understood and for that purpose it is necessary to have information.

This reality obviously transforms the total privacy in an impractical solution in our consumption society; if a company or other organization (e.g. non-profit, political, governmental, etc.) intends to satisfy its customers or voters, it needs to obtain the best information possible about them.

Probably, one of the main advantages of electronic business over the traditional forms of negotiation is based on the ability to digitally customize the commercial offers. This is often possible thanks to the information gathered in a process that Peppers and Rogers (1999) named "Marketing One-to-one". We could think that the majority of the companies operating online know much more about their customers than the ones who operate exclusively offline. Many times these know almost nothing about their customers. In the mass markets of the industrial age, bookstores and supermarkets that operate exclusively in the physical world (doing commerce without using digital resources) has been dealing with customers that are practically anonymous as far as those merchants know. Such clients can choose and pay for the products but the most of the time nobody knows anything about their particular preferences and expectations. Very different is the situation that takes place in the virtual world. In fact, online traders (e.g. in www.amazon.com) know almost everything (desirable just what is business related of course) about their customers. They know their names, addresses, preferences, purchase historical, requirements of the delivery conditions, preferred types of payment, etc.

Meanwhile, this access to knowledge is seldom attained without a 
cost. In the limit, this cost can be dramatic, because if there are sufficient resources devoted to a particular investigation, few pieces of personal information remain secret for anyone willing to use any immoral means to obtain them. Thus, it looks like it's not possible to get the best of both worlds, i.e., enjoying the maximum convenience while assuring complete privacy.

On the one hand, the possession of detailed information about customers, allows companies to create personal profiles that lead to a better service rendering. This way, these companies can provide consumers personalized offers. However, on the other hand, these situations cause high risks associated with the handling of personal data, which is an especially important issue for companies with exclusive presence on the Internet.

Often, these companies do not have many more assets beyond databases with detailed information about its customers. For example, in a situation where these companies face financial problems, it is worrying to see that the only assets that can be alienated are those databases.

Faced with these and other vicissitudes, one could think that the fundamental ethical objective is to achieve a balance between the "need to know" and the "right not to divulge".

\subsubsection{Optimizing the Trade-OfF}

One of the tactics for optimizing the trade-off between "Privacy" and "Convenience" is to encrypt the data that needs to be protected, for example, by using a public key and a private one. The public key is just to encode the message, being the decoding made thanks to a private key that never leaves the hands of its owner. In spite of the recognized importance of this tactic, we think that to protect the right to privacy in the information age, is especially needed the creation of mechanisms that facilitate a self-regulation of ethical-legal parameters of the virtual world. The conception of 
software that incorporates those ethical and legal considerations seems to be the best way to achieve this objective. For such an achievement, Barroso (2001) offers us the figure of an "ethical computer engineer", as being an entity able to apply the most appropriate technologies to safeguard the desired privacy.

Still aiming for optimize the balance between "Privacy" and "Convenience", we think we should consider a trend that can be of crucial importance to understand how to deal with modern privacy concerns. It seems that the increasing numbers and the so extraordinary adherence of social networking users is changing the societal nature of the balance between the "need to know" and the "right not to divulge". Christofides et al. (2009) states that "Online social networks sites such as Facebook, are changing the nature of social relationships [...] research about disclosure and privacy in the Facebook environment suggests that despite privacy concerns, individuals disclose great deal of personal information" (pp. 341342).

Today, the younger individuals appear to be less concerned about their privacy than the previous generations, and they show interest in making the referred trade-off, the same that sacrifices their privacy for the benefit of their convenience. We think that this happens partly because, for these young people, such a sacrifice does not seem to be a major problem. For example, in the social network Facebook, adolescents seem particularly interested in making the referred trade-off, giving up their privacy to be able to benefit from an added convenience and to achieve the confidence of their peers (Yourn, 2005). Also Henderson and Gilding (2004) consider that "there is a reciprocal relationship between trust and self-disclosure in online communication" (p. 488). As stated by Christofides et al. (2009), "Information disclosure increases the impression of trustworthiness and results in reciprocal personal disclosure on the part of the conversation partner" (p. 342). Qualman (2010), goes further, affirming that "the younger the generation, the less concerned with privacy issues is" (p. 22). This author emphasizes the importance of this idea by quoting Bill Tancer, general director of Global Research of the company Hitwise: 
"If you can make some things more important to me, although losing some privacy, well, it's a small price to pay." (p. 22). From an ethical perspective, we think that this trade-off deserves full investigation.

Recent developments on the Web 2.0 platform with the increasing implementation of open source software (whose importance in the new digital economy has already been highlighted in this chapter), provides greater convenience in terms of Business Social Networking. Nevertheless, as a reverse of the medal, a major difficulty arises from an ethical point of view: since all the new applications available in social networks (and there are already millions) can now be developed and implemented individually by programmers from all over the planet (e.g. applications for the iPhone, the known mobile device from Apple company), it becomes imperative the extra work of ensuring that each of these applications safeguards the privacy level desired by each user. For that reason it is crucial the professional commitment of those who are responsible for social networks, which must be governed by its own code of ethics and promote a self-regulation that encourages an ethical participation of all users. After all, without a moral responsibility capable of accepting the sacred nature of the right of individuals to the privacy of their private lives and to the information they wish will remain confidential, the business practice on the Internet will constitute a continuing threat from an ethical point of view, subsisting always the risk of someone invading the privacy of others. 


\section{CONCLUSIONS}

The digital interactivity ubiquity and the unprecedented level of social and business networking, which has been made possible by Internet, are altering the economic system premises and the current requirements for business competitiveness. The effects of these changes are still uncertain, and the range of conjectures goes from the glimpse of self-organized monopolies up to the more auspicious prediction of new business models that will be useful to society as a whole and easily accessible for many creative entrepreneurs.

Digital reproduction entails extremely low costs and that can represent very different business opportunities in the 21st century. For some, these low costs also may threaten the industrious spirit of those who foresee the possibility that others will just copy them and collect the fruits of their labour. We are not sure about this lethargic trend because it is known that necessity is the mother of invention... Anyway, we believe that profound economic changes may already be in progress, resulting from new collaborative forms of working and socializing in the virtual world as well as behavioural changes are emerging and changing the landscape of business best practices in the information age.

Nowadays, as it is known, individuals show their profiles and personalities with unusual ease, exposing their own daily lives in virtual communities like Facebook, Linkedln or Twitter, and this new reality is giving new shape to old ethical issues, being also in the origin of ethical and regulatory dilemmas that never have been so worrisome in the industrial age. Hence, were pointed out four problematic ethical subjects, mnemonically initiated by the letter "P", which are the following "Cyberethics-mix" elements:

1. Property of intellectual rights over digitized contents

The intellectual property dilemma revolves around the dichotomy between the protection of intellectual ownership rights and the 
public interest. On behalf of pragmatism, it should be noted that regardless any of these points of view, it becomes practically impossible to prevent someone (even anonymously) from making unauthorised copies and spread them over the Internet. At the same time, the competitive environment calls for creativity and a crossfertilization of projects and ideas coming from different minds and different owners... Here, the previous legal framing does not seems to help and some less restrictive approaches are paving their legal way.

2. Precision of the content and data made available on the www

The current ease to create and distribute digital content seems to contribute to a lack of precision and a high level of misinformation. The diffusion of a growing volume of information, can hide the difference between important and trivial, and between truth and false. We think that the main strategies to address the paradoxical scourge of the "misinformation in the Information age", should aim for develop the critical sense of "Internauts" and create reliable indicators about the authority, reliability and credibility of content providers, increasingly atomized through digital emancipation.

\section{Possibility to access the on-line information flow}

The possibility of access to the information on Internet social networks is a powerful instrument, constituting a key asset in the pursuit of organizational and individual goals. Nevertheless, there are cases where this access should be limited. For example, the protection of minors on Internet social networks certainly deserves further consideration. Meanwhile, there is some hope around the kindness of a regulatory impact coming from appropriate software that can assure an adequate filtering. If it is used prudently, this software can contribute to a self-regulation of ethics in the information era.

\section{Privacy of personal data on Internet networking}

The last element of the mentioned "Cyberethics-mix" refers to the 
privacy of Internet users in general and of social networks members in particular.

The attack on the basic right to personal and family life privacy is perhaps one of the most pressing issues from an ethical point of view in this dawning of the information age. If it is true that complete privacy is not a practical solution in our consumption society, and that the loss of some privacy may be the price to safeguard the consumer convenience (the consumer needs can only be fully satisfied after they have been well understood), also seem certain that some individuals and organizations will not renounce to their opportunistic impulses and will attempt to achieve their interests without respecting the privacy of others. Therefore, a balance is needed between the "need to know" and the "right not to divulge". This balance can pass not only by the implementation of certain technological solutions (e.g. data encryption), but also by the adherence to certain types of software that may ensure a decentralized effort of ethics self-regulation in the virtual world.

The social and business impacts of the advances in comunication and information technologies are an ethical heated topic of debate. We think that technology progress will atomize the social and economic fabric, personalizing even further the society and creating heterogeneous business opportunities that will increase the consumer's available choice. On the contrary, there are others who consider that the electronic mediation will boost the hegemony of the large firms and standardize social interaction and the consumption patterns. For sure, these issues will continue to merit further investigation.

It seems certain that ethical reflection and measures taken to reduce the uncertainty and insecurity of users are aspects that contribute to increase the level of trust in digital networks on the Internet, a factor which is deemed necessary to induce the best practices concerning business social networking. We believe that is necessary an inter-penetration of ethical and virtual dimensions and we think that the role played by ethical guidelines in this desideratum should be emphasized. We consider that is also highly 
recommended an extensive investigation of technological supports that allow a full integration of ethic principles in building virtual communities, favouring a self-regulation of ethical behaviour in business practices on social networks over the Internet. 


\section{REFERENCES}

Anderson, C. (2009). Free: o futuro é grátis. Lisboa: Actual Editora;

Avatar. (2010, Jun 20). In Wikipédia, the free encyclopedia.

Retrieved August 27, 2010, from

http://en.wikipedia.org/wiki/Avatar_(computing) ;

Barroso, P. (2001). Cyberethics: Ethical Problems with New Technologies. Paper presented at the Conference ETHICOMP 2001: "Systems of the Information Society". Gdansk, Poland;

Begg, M., Rogerson, S., Fairweather, N. (2001). Towards Protecting Children in Cyberspace. Paper presented at the Conference ETHICOMP 2001: "Systems of the Information Society". Gdansk, Poland;

Blogosphere. (2005, Nov, 14). "In Wikipédia, the free encyclopedia. Retrieved July 30, 2010, from http://en.wikipedia.org/wiki/Blogosphere;

Bonsón, E., \& Flores, F. (2010). Social Media Metrics and Corporate Transparency. Online, 34(4), 23-25. Retrieved from Academic Search Complete database;

Brandeis, D., \& Warren, S. (1890) The Right to Privacy. Harvard Law Review. Vol. IV December 15, No. 5;

Christofides, E., Muise, A., Desmarais, S. (2009). Information Disclosure and Control on Facebook: Are They Two Sides of the Same Coin or Two Different Processes?. CyberPsichology \& Behavior, 12 (3), 341-342;

Creative Commons. (2010). In the CreativeCommons website. Retrieved September 1, 2010, from http://www.creativecommons.pt/; 
Delicious (website). (2010, Aug 19). In Wikipédia, the free encyclopedia. Retrieved Sep 6, 2010, from

http://en.wikipedia.org/wiki/Delicious;

Digg. (2010, Sep 10). in Wikipédia, the free encyclopedia.

Retrieved September 14, 2010, from

http://en.wikipedia.org/wiki/Digg;

Dreyfus, H. (1999). Anonymity Versus Commitment: The Danger of Education on the Internet, Ethical and Information Technology, March, 1, 1999;

Facebook. (2010, Set 12). In Wikipédia, the free encyclopedia.

Retrieved September 6, 2010, from

http://en.wikipedia.org/wiki/Facebook;

Flickr. (2010, Set 7) In Wikipédia, the free encyclopedia. Retrieved September 8, 2010, from http://en.wikipedia.org/wiki/Flickr;

Google Search. (2010, Sep 14). ). In Wikipédia, the free encyclopedia. Retrieved Sep 14, 2010, from http://en.wikipedia.org/wiki/Google_Search;

Henderson, S., \& Gilding, M. (2004). "I've never clicked this much with anyone in my life": trust and hiperpersonal communication in on-line friendship. New media and Society, 65: 487-506;

Http Cookie. (2006, May 8). In Wikipedia, the free encyclopedia. Retrieved August 25, 2010, from

http://en.wikipedia.org/wiki/HTTP_cookie;

Jarvis, J. (2010). O Que Faria o Google. Lisboa: GestãoPlus Edições;

Johnson-Lenz, P., \& Johnson-Lenz, T. (1982), Groupware: The process and impacts of design choices. In Computer-Mediated Communications Systems: Status and Evaluation. New York: Academic Press; 
Johnson-Lenz, P., \& Johnson-Lenz, T. (2010). Groupware:Coining and Defining It. Response to an inquiry from the Oxford English Dictionary. Awakening Technology Website, April 1994. Retrieved July, 12 from

http://nexus.awakentech.com:8080/at/awaken1.nsf/UNIDs/1 AAC0F50 A95547878825667E0001A3C2?OpenDocument;

Keen, P., \& McDonald, M. (2000). The eProcess Edge. New Jersey: McGraw-Hill;

Kierkegaard, S. (1967). Soren Kierkegaard's Journal and Papers. Indiana: Indiana University Press;

Kotler, P., \& Keller, K. (2005). Marketing Management. 12 th edition. New Jersey: Prentice-Hall;

Lessig, L. (1999). Code and other Laws of Cyberspace. New York: Basic Books

Linkedin. (2010, Set 5). In Wikipédia, the free encyclopedia.

Retrieved September 6, 2010, from

http://en.wikipedia.org/wiki/Linkedln;

Many-to many. (2007, Jun, 14). In Wikipédia, the free encyclopedia. Retrieved August 28, 2010, from http://en.wikipedia.org/wiki/Manyto-many;

Marturano, A. (2002). The role of metaethics and the future of computer ethics. Ethics and Information Technology, 4(1), 71-78;

Metcalfe, B. (1995). Metcalfe's Law: A network becomes more valuable as it reaches more users. Infoworld, Oct. 2, 1995;

Murphy, W. (2004). Self-Organizing Systems in the Information Age: Will the Economics of the Information Age Foster Monopolies and 
Should Anyone Care? Paper presented at the Irish Association of Law Teachers Annual Conference, Derry, Northern Ireland;

Newman, J. (2000). "Who is the best connected scientist? A study of scientific co-authorship networks", Working Paper, Santa Fe Institute;

Odlyzko, A., \& Tilly, B. (2006). A refutation of Metcalfe's Law and a better estimate for the value of networks and network interconnections. Digital Technology Center, University of Minnesota. Retrieved June, 28, 2010, from http://www.dtc.umn.edu/odlyzko/doc/metcalfe.pdf;

Peppers, D., \& Rogers, M. (1999). Enterprise One to One : Tools for Competing in the Interactive Age. New York: Doubleday;

Prosser, B., \& Ward, A. (2001). Fear and Trembling on the Internet. Paper presented at the Conference ETHICOMP 2001: "Systems of the Information Society". Gdansk, Poland;

Prosumer. (2008, Apr, 10). In Wikipedia, the free encyclopaedia. Retrieved Sep 10, 2010, from http://en.wikipedia.org/wiki/Prosumers

Qualman, E. (2010). Socialnomics. Como os media sociais estão a transformer o modo como vivemos e como fazemos negócios. Lisboa: Editorial Presença;

Russel, B. (1931). The Scientific Outlook. New York: Norton;

Skype. (2010, Set, 9). In Wikipédia, the free encyclopedia. Retrieved September 10, 2010, from http://en.wikipedia.org/wiki/Skype;

Spinello, R. (2001). Morality, Markets, and the Internet. Paper presented at the Conference ETHICOMP 2001: "Systems of the Information Society". Gdansk, Poland;

Surowiecki, J. (2004). A Sabedoria das Multidões. Lisboa: Lua de Papel; 
Szalavitz, M. (1999). Can We Become Caught in the Web. Newsweek, December, 1999;

Tapscott, D. et al. (2007). Wikinomics. USA: Penguin Books;

Twitter. (2010, Sep 4). In Wikipédia, the free encyclopedia. Retrieved September 6, 2010, from http://en.wikipedia.org/wiki/Twitter;

Warren, S., \& Brandeis, L. (1890). O Direito à Privacidade, Harvard Law Review;

Wauters, R. (2010). Zuckerberg Makes It Official: Facebook Hits 500 Million Members. Posted in TechCrunch Website on July 21. Retrieved July 29, 2010, from http:/techcrunch.com/2010/07/21/facebook-500-million/;

Web 2.0. (2010, Sep 14). In Wikipédia, the free encyclopedia. Retrieved September 14, 2010, from http://en.wikipedia.org/wiki/Web_2.0;

Wikipedia. (2010, Set, 14). In Wikipédia, the free encyclopedia. Retrieved September 14, 2010, from http://en.wikipedia.org/wiki/Wikipedia;

Yourn, S. (2005). Teenagers'perceptions of online privacy and coping behaviours: a risk-benefit appraisal approach. Journal of Btroadcasting \& Electronic Media. 49:86 - 110. 


\section{KEY TERMS}

"Cyberethics" - Ethics in electronic space or virtual world.

Digital paradigm - Pattern of reality that results from a sampling process encoded in binary language. Unlike the analog paradigm, characteristic of a physical reality composed of complex signs that are not yet computable, the digital paradigm is reflected in a virtual reality composed entirely by computable finite groups of just two different signals ( 0 and 1 ).

Business models - Method or process of negotiation through which one intends to generate income. It is the manner by which the value can be created and collected.

Transaction costs - Costs that companies incur when they use outside suppliers instead of doing things internally. When is cheaper to do things externally, companies downsize. The digital paradigm is characterized by inducing low transaction costs (many times even zero).

Web 2.0 - The second generation of the World Wide Web, mainly composed by dynamic and shareable content, as well as by social networking applications.

Open-code software - Computer software available within the public domain, developed in a public and collaborative manner.

Trade-off - Balance between something we want and something we have to sacrifice correspondingly. That's the case occurring between privacy and convenience. 


\section{ENDNOTES}

${ }^{1}$ Product, Price, Promotion and Place, are the four elements of a mnemonical model created by Philip Kotler, known as the "marketing mix" (Kotler \& Keller, 2005).

${ }^{2}$ This term is of unknown authorship and intends to designate the traditional ethical principles when applied to the field of information technologies. Most of these principles dated back to Socrates and Aristotle.

${ }^{3}$ World Wide Web

${ }^{4}$ Author's translation.

${ }^{5}$ In July 2010, the social networking site Facebook had more than 500,000 users and this number continues to increase. Mark Zuckerberg, the founder of this social network, believes that the threshold of one billion users is almost guaranteed (Wauters, 2010).

${ }^{6}$ Prosumer is a portmanteau formed by contracting either the word professional or producer with the word consumer." ("Prosumer", 2010, para. 1).

7 Metcalfe's law states that the value of a telecommunications network is proportional to the square of the number of connected users of the system $\left(n^{2}\right)$ (Metcalf, 1995).

${ }^{8}$ The many different ways to satisfy the customer needs and take advantage of this new tendency for "free" is a controversial subject of modern marketing (and one of the favorite fields of study of the author of these lines), but that exceeds the scope of this chapter and therefore it will not be further detailed.

${ }^{9}$ Author's translation.

${ }^{10}$ Author's translation.

${ }^{11}$ Author's translation.

12 An avatar is a computer user's representation of himself/herself or alter ego whether in the form of a three-dimensional model used in computer games, a twodimensional icon (picture), or a one-dimensional username used on Internet forums and other communities [...] It is an object representing the user. The term "avatar" can also refer to the personality connected with the screen name, or handle, of an Internet user." ("Avatar (computing)", 2010, para. 1).

${ }^{13}$ Technology contributor for The CBS Early Show and senior editor on CNET TV ${ }^{14}$ Author's translation.

15 "[Cookies are] pieces of text stored by a user's web browser. A cookie can be used for authentication, storing site preferences, shopping cart contents, the identifier for a server-based session, or anything else that can be accomplished through storing text data" ("HTPP Cookie", 2010, para. 1). "Cookies can be used to track people-a privacy concern" ("HTPP Cookie", 2010, para. 4).

16 "Many-to-many is an expression that describes a communication paradigm and an associated media form. With [web 2.0] developments [...] a new set of Internet applications enable: [i] people to both contribute and receive information. [ii] information elements can be interlinked across different websites. This kind of 
Internet application shows the beginning of the "many-to-many" paradigm. With the evolution to the full "many-to-many" computing paradigm, people can input and receive information to and from the Internet; they will be able to connect and communicate dynamically within a flexibly formed scope; there will be no artificial boundary between information and communication tools, and the definition of "many" will go well beyond people to include entities such as organizations, products, processes, events, concepts and so on" ("Many-to-Many", 2007, para 1).

${ }_{17}$ The blogosphere is made up of all blogs and their interconnections. The term implies that blogs exist together as a connected community (or as a collection of connected communities) or as a social network in which everyday authors can publish their opinions ("Blogosphere", 2005, para 1).

${ }_{18}$ Author's translation.

${ }^{19}$ The founder and owner of Facebook.

20 Author's translation.

21 "Linkedln is a business-oriented social networking site. Founded in December 2002 and launched in May 2003, it is mainly used for professional networking. As of 9 August 2010, Linkedln had more than 75 million registered users, spanning more than 200 countries and territories worldwide." ("Linkedin", 2010, para 1)

${ }_{22}$ "Facebook is a social networking website launched in February 2004 that is operated and privately owned by Facebook, Inc., with more than $\mathbf{5 0 0}$ million active users in July 2010. Users can add people as friends and send them messages, and update their personal profiles to notify friends about themselves. Additionally, users can join networks organized by workplace, school, or college." ("Facebook", 2010, para 1)

${ }_{23}$ "Flickr is an image hosting and video hosting website, web services suite, and online community created by Ludicorp later acquired by Yahoo!. In addition to being a popular website for users to share and embed personal photographs, the service is widely used by bloggers to host images that they embed in blogs and social media. As of October 2009, it claims to host more than 4 billion images." ("Flickr", 2010, para 1)

${ }^{24}$ "Skype is a software application that allows users to make voice calls over the Internet. Calls to other users within the Skype service are free, while calls to both traditional landline telephones and mobile phones can be made for a fee using a debit-based user account system. Skype has also become popular for its additional features which include instant messaging, file transfer, and video conferencing." ("Skype", 2010, para 1)

${ }_{25}$ "Twitter is a social networking and microblogging service [...] that enables its users to send and read other users' messages called tweets. Tweets are textbased posts of up to 140 characters displayed on the author's profile page. Tweets are publicly visible by default, however senders can restrict message delivery to their friends list. Users may subscribe to other author tweets-this is known as following and subscribers are known as followers. As of late 2009, users can follow lists of authors instead of following individual authors." 
(“Twitter", 2010, para 1)

${ }^{26}$ Author's translation.

${ }_{28}^{27}$ Author's translation.

${ }_{28}$ "Wikipedia is a free, web-based, collaborative, multilingual encyclopaedia project. [...] Its 16 million articles have been written collaboratively by volunteers around the world, and almost all of its articles can be edited by anyone with access to the site. [Wikipedia] is currently the largest and most popular general reference work on the Internet." ("Wikipedia", 2010, para 1)

${ }^{29}$ This mnemonical nomenclature was inspired by another one, created by Philip Kotler, who was known for the four-letter "P" of the Marketing-Mix (Kotler, 2005).

${ }^{30}$ This was the first battle in a complicated legal war with regard to issues related to intellectual property. Having worked between June 1999 and July 2001, the website napster.com was the first truly popular program for sharing music files in MP3 format. For facilitating the upload and download of copyrighted music, Napster was accused by the music industry for violating these rights and was eventually closed down by court order. However, this website has proved to be just "the tip of the iceberg", making the way for many similar programs that allow you to share books, movies, etc. In fact, all types of intellectual property that can be digitalized are as vulnerable as music, inviting the appearance of facilitating agents of these trades much more difficult to control (e.g. Kazaa, Emule, Limewire, Morpheus, etc.). It is believed that in this case, the great ethical dilemma is to know how to deal with a phenomenon that clearly shows that there are millions of citizens willing to appropriate and offer the intellectual property of others.

${ }^{31}$ In this website, we can read that "MIT OpenCourseWare makes the course materials that are used in the teaching of almost all MIT's undergraduate and graduate subjects available on the Web, free of charge, to any user anywhere in the world.

MIT OpenCourseWare is a large-scale, Web-based publication of MIT course materials, and is not a degree-granting or credit-bearing initiative.".

32 Obviously, excessive deviation from tradition consecrated by time, are punished with extinction. As any biologist well knows, there is an optimum value for the mutation rate of a species, because its evolution only occurs when this rate can be situated between the overwhelming order and the destructive chaos. For many species of the biosphere, including humans, the mutation rate has been in balance in this very area. We think that this "zone" is moving rapidly in the business world and demanding a corresponding increase in the rate of business innovation.

33 "The term Web 2.0 is commonly associated with web applications that facilitate interactive information sharing, interoperability, user-centered design and collaboration on the World Wide Web. A Web 2.0 site gives its users the free choice to interact or collaborate with each other in a social media dialogue as creators (or "prosumers") of user-generated content in virtual communities in contrast to websites where users (consumers) are limited to the passive viewing 
of content that was created for them." ("Web 2.0", 2010, para 1).

${ }_{34}$ "Digg is a social news website. Formerly, the site's cornerstone function consisted of letting people vote stories up or down, called digging and burying, respectively, but as of Digg v4, the "bury" function has been removed. Also, as of v4, users can no longer see all of the submitted content, but must instead subscribe to a user's feed to see what has been submitted. Digg's popularity has prompted the creation of other social networking sites with story submission and voting systems." ("Digg", 2010, para 1).

35 "[Delicious (website)] is a social bookmarking web service for storing, sharing, and discovering web bookmarks. [...] By the end of 2008, the service claimed more than 5.3 million users and 180 million unique URLs bookmarked." (“Delicious (website)", 2010, para 1).

36 "Google's rise to success was in large part due to a patented algorithm called PageRank that helps rank web pages that match a given search string. Previous keyword-based methods of ranking search results, used by many search engines that were once more popular than Google, would rank pages by how often the search terms occurred in the page, or how strongly associated the search terms were within each resulting page. The PageRank algorithm instead analyses human-generated links, assuming that web pages linked from many important pages are themselves likely to be important. The algorithm computes a recursive score for pages, based on the weighted sum of the PageRanks of the pages linking to them. PageRank is thought to correlate well with human concepts of importance. In addition to PageRank, Google over the years has added many other secret criteria for determining the ranking of pages on result lists, reported to be over $\mathbf{2 0 0}$ different indicators. The details are kept secret due to spammers and in order to maintain an advantage over Google's competitors. (“Google Search", 2010, para 4)

${ }^{37}$ Author's translation.

${ }_{38}$ Aspects such as "spamming", lack of privacy, unauthorized copy, misinformation and so many other manifestations of the absence of mechanisms that force the companies to put in perspective questions of ethical, moral and social nature.

${ }^{39}$ Costs related, for example, with information gathering, organization of the affected parties, monitoring and supervising the implementation of regulatory measures, etc..

${ }^{40}$ Replacing either the "visible hand" of the law, which in the face of technological change is almost always reactive and slow, either the "invisible hand" of the market, which often reveals little touch to the social costs (Spinello, 2001). 